\title{
El hombre y la tierra: naturaleza de la realidad geográfica
}

\author{
Dardel, E. (2013). El hombre y la tierra: naturaleza de la realidad geográfica. Joan Nogué (ed.);
}

María Beneyto (trad.); Jean-Marc Besse (introd.). Madrid: Biblioteca Nueva.

\author{
Oscar David Gómez Maury*
}

Si El hombre y la tierra de Dardel no hubiese pasado "desapercibido en el momento de su publicación [...]” (p. 13) en 1952, como lo afirma Joan Nogué en la presentación del libro a continuación reseñado, seguramente la geografía regional francesa y la ciencia positiva imperante en la época habría dado un giro que permitiera abrir el campo de posibilidades para un diálogo metodológico y epistemológico entre ciencia positiva y fenomenología para pensar no solo el espacio en relación al hombre, sino su amplia gama de manifestaciones (de Ser-enel-mundo) que a lo largo de la historia humana ha tenido como tendencia; sería esta una poética que, aunque precoz, despertaría conciencia sobre un universo simbólico que es propio de un sujeto y, además, de la interacción entre el hombre y la tierra.

Es en este sentido, como Dardel despliega ante el lector sus diversos intereses académicos, como la enseñanza, reflexiones históricas y filosóficas (centrado en la fenomenología de Heidegger) respecto al espacio, el universo simbólico que en él se encuentra retratado, el paisaje, la concepción de mundo y sus habitantes, tierra, entre otros; lo cual aporta una mirada enriquecedora a la relación hombre-espacio y lo que se vuelve fenómeno ante él, como el paisaje.

La reedición de este libro elaborada por Joan Nogué consta de dos apartados principales sin contar la presentación del libro. En primer lugar, se presenta un estudio de la obra de Eric Dardel, realizada por Jean-Marc Besse, interesado en la investigación de temas relacionados con historia, filosofía y, recientemente, el paisaje. Este primer apartado resulta sugestivo puesto que se dialoga con Dardel mismo para interpretar su obra, en virtud del concepto de existencia y su relación con ese ser geográfico que se resalta mediante el concepto de geograficidad e historicidad, entendido el primero como la conciencia que se tiene sobre el espacio, y, el segundo, sobre el tiempo. Además, se sitúa el pensamiento geográfico del autor a modo de ciencia hermenéutica, en la medida que la geografía debe interpretar la naturaleza, lo cual implicaría develar los elementos constitutivos del espacio geográfico, el paisaje y las interacciones del hombre en el lugar, de modo que el campo científico se amplía y se enriquece mientras se explora la obra de Dardel.

La segunda parte es propiamente el trabajo del autor, dividida en tres capítulos, el primero se relaciona con el espacio geográfico, que trata en ocho subtemas los tipos de espacio que interactúan entorno a la realidad geográfica: espacio geométrico, material, telúrico, acuático, aéreo, construido, la constitución paisaje y la realidad geográfica. En este orden podemos encontrar que la concepción de espacio geográfico se puede entender como lo que es en cuanto que es, en otras palabras, lo que es concreto, como por ejemplo París, el Sahara, el Mediterráneo, es todo aquello que tiene horizonte, color, forma, donde es todo diferenciado. El espacio geográfico es netamente distinguido del espacio geométrico, ya que este último es uniforme, neutro y homogéneo. En consecuencia, el autor esgrime una contundente crítica al orden científico de la geografía en la medida que separa al hombre del espacio, le arrebata en cierta medida la posibilidad de explorar e interesarse por el mundo que lo rodea, como otrora los navegantes y aventureros lo hacían.

Dardel argumenta que la geografía no solo es reconocer lo terrestre, sino hacerlo fenomenológico, hacer de la geografía una experiencia a partir de la poética. El hombre construye su espacio material a imagen de sus costumbres y sus costumbres son moldeadas a partir de lo material, a partir de una naturaleza geográfica, la cual tiene unos pilares que se aferran del interior de la tierra (profundidad), es decir, del espacio telúrico, no es

\footnotetext{
* Integrante del semillero de investigación Scripta Geographica-Grupo Interinstitucional de Investigación Geopaideia.
} 
únicamente superficie de la que se compone el espacio, existe lo sólido, el relieve que permite comprender que "la tierra como realidad telúrica no es estática” (p. 75), posee movimiento.

El espacio acuático referencia principalmente lo que es inseparable de la vegetación, en cuanto que el agua expresada en ríos, mares y océanos ha sido una extensión de la conquista del hombre por su espacio, pero ante todo es vida que se va meciendo al ritmo de las mareas. Posteriormente, dice el autor, "el espacio aéreo es un espacio portador donde flotan las nubes, de donde cae la lluvia. Desde tiempos inmemoriales, el hombre ha soñado con volar. Ha sido en el siglo xx cuando ha podido abrir nuevas rutas" (p. 85), de este modo cobra importancia ya que se relaciona con la atmosfera y envuelve la existencia, en ella se encuentran los olores, la temperatura, y todo aquello que puede seducir los sentidos. El espacio construido como "obra del hombre" (p. 86) deja entrever que "[...] la forma más importante de espacio construido va unida al hábitat del hombre" (p. 86), irremediablemente se construye para hacer de la existencia humana, destino y desenvolvimiento de la acción humana, en tanto se conciba la condición terrestre del hombre. Aquí es cuando la tierra se considera sustento básico del sujeto, circunstancia y, el paisaje, como forma de expresión del espacio terrestre ya que encarna todo lo que rodea a ese sujeto geográfico. Se puede decir con todo esto que dichos espacios son dinamizadores no solo del paisaje en sí mismo, sino de la realidad y naturaleza geográfica, donde el movimiento o el cambio es una constante.

En el segundo capítulo, "Historia de la geografía", Dardel trata distintos enfoques de la geografía que se han dado a lo largo de la historia, ya que, como el autor hace entender, cada época posee una imagen admitida de la forma terrestre, determinada interpretación. Para ello, divide el apartado en cinco subtemas: el primero de ellos refiere a la geografía mítica, ella es en extremo interesante porque aparte de narrar los orígenes en la concepción del mundo, el autor enfatiza sobre la no separación entre hombre y tierra, ya que el mito reviste al hombre como un ser que depende bastante de la tierra en el sentido de una relación afectiva con la misma, por lo que para sostener este argumento se encuentra estrechamente asociado al mito. De aquí que, en la geografía mítica, la tierra posea cinco principales características: origen (de dónde venimos), presencia (posibilidad de lo creado), poder sobrenatural, principio y unidad de grupo, y ausencia de direcciones absolutas. En este sentido, el mundo empieza como un gran desorden que luego se va organizando en múltiples representaciones colectivas de distintos pueblos, por ejemplo, la mitología griega o nórdica.

Como segundo subtema, en relación con las representaciones de mundo, se encuentra la tierra como interpretación profética. En ella se anuncia la llegada de una nueva era, el lugar se vuelve histórico, como el monte Sinaí, el Jordán o la Tierra Prometida, el anuncio que se hace sobre los lugares toma protagonismo porque se temporalizan los espacios concretos. El cuarto subtema aborda la geografía heroica, entendida como la "comprensión de la Tierra en la que el espacio geográfico es considerado como espacio por descubrir, llamada a la aventura, ampliación de la estancia terrestre fijada por la tradición y la vida de grupo" (p. 134), esta se encuentra aún atada a concepciones mítico-mágicas y un sentido de la aventura, ya que esta es la que posibilita la exploración, al pasar del tiempo esta toma un matiz legendario; a finales de siglo xv y mediados de siglo xvi se dio una revolución geográfica entre los viajes de Cristobal Colón y Américo Vespucio, esto logró sedimentar lo que más adelante sería aclarar los misterios de tierras desconocidas.

Para el cuarto subtema, titulado "La geografía de campo", logra ser bastante diciente en la medida que el estudio del espacio geográfico se centra en una sistematización del conocimiento de las tierras conocidas, en donde los exploradores fueron a misiones científicas con el objetivo de poder estudiar lo que observaban en las exploraciones. En este sentido, nace lo que Dardel en el último subtema denomina geografía científica, presentada como opuesta al descubrimiento geográfico porque existe un orden lógico que se somete a leyes que no varían, aquel conocimiento geográfico primario de explorar el mundo logra reducirse a una geografía de inventario, donde se trabaja en un laboratorio con mapas y gráficos.

El tercer capítulo expone las conclusiones. En este Dardel realiza fuertes críticas a la llamada geografía científica, que pretende ser del todo objetiva por el simple hecho de separar el sujeto del objeto de estudio desde la tradición cartesiana, reduciendo el espacio a objeto o "la Tierra en materia prima o en fuente de energía industrial” (p. 164). Cabe aclarar que el autor no pretende dejar de lado la objetividad científica, ya que, en palabras suyas, "la geografía, por su posición, no puede evitar debatirse entre el conocimiento y la existencia. Apartándose de la ciencia, se perdería en la confusión y la charlatanería" (p. 170), en este sentido se busca humanizar, darle vida al estudio de lo geográfico, en donde el hombre pueda ser consciente de su espacialidad.

Para finalizar, este libro aporta un elemento metodológico y estético de gran valor desde su narrativa, en la medida que para expresar lo fenomenológico se hace uso de la literatura para poderla concatenar con el espacio, la realidad y naturaleza geográfica. Es tambien interesante poder realizar la lectura de este texto pensando en cómo pudo haber sido la geografía regional francesa si lo expuesto por Dardel se hubiera desarrollado en aquella época y no en estos tiempos, posiblemente el curso de la historia pudo haber reconciliado la ciencia positiva y la fenomenología, el sujeto y el objeto sin perder rigor científico. Por otro lado, sin duda el texto puede establecer un derrotero importante en la construcción de un sujeto que piense el espacio donde interactúa, ya que en condición terrestre si se conquista el entorno, se puede desbordar elementos como la técnica científica en cuanto que el sujeto retorna al espacio, hace parte de él, lo vive y deja de ser un medio, para poder ser fin en sí mismo. 